\title{
Identifikasi Permasalahan yang Dihadapi oleh Anggota Forum Silaturahmi Peternak Kambing di Sumatera Barat
}

\section{The Identification of Problems Affecting Goat Farmers' Friendship Forum in West Sumatra Province}

\author{
F. T. Intano ${ }^{1}$ dan F. Madarisa ${ }^{2 *}$ \\ ${ }^{1}$ Program Magister Ilmu Peternakan Fakultas Peternakan Universitas Andalas, Padang, 25163 \\ ${ }^{2}$ Fakultas Peternakan Universitas Andalas, Padang, 25163 \\ *E-mail: fmadarisa@gmail.com
}

(Diterima: 09 Mei 2018; Disetujui: 3 Agustus 2018)

\begin{abstract}
ABSTRAK
Satu kajian awal telah dilakukan untuk mengidentifikasi permasalahan yang dihadapi oleh peternak anggota forum silaturahmi peternak kambing Sumatera Barat(FSPKSB). Data primer dikumpulkan memakai pendekatan partisipatif yang diambil dari konsep 'proses belajar sosial' untuk dua tujuan; (1) mendapatkan informasi mendalam tentang pemeliharaan ternak dan (2) upaya untuk memperbaiki kesadaran dikalangan 28 orang peternak anggota forum. Analisa data menggunakan kerangka logis dengan pengungkapan secara deskriptif rasional. Hasil kajian adalah peternak kambing menghadapi sejumlah masalah, terdiri dari; mutu bibit, penyediaan pakan, pencegahan penyakit, perluasan pasar untuk menambah produksi dan peningkatan kapasitas kelembagaan serta kebijakan pendukung. Transformasi untuk merevitalisasi pengelolaan agribisnis ternak kambing mestinya mewujudkan proses dan produk yang standar. Hal ini sesuai dengan aturan perundang-undangan dari lembaga berwenang.
\end{abstract}

Kata kunci: masalah peternak kambing, organisasi peternak, perencanaan

\section{ABSTRACT}

A preliminary study had been carried out to identify problems affecting daily activities of the goats farmers participating in friendship forum of West Sumatra province. Using a participative approach, both collecting data and concept of social learning process were conducted to achieve two points; (a) thorough information on keeping goats and (b) a better consciousness among 28 persons of goat friendships, organization members. A descriptive expression with a logical framework was followed to analyse data. The results showed that goat farmers faced a number of problems namely; breedings quality; feeding supply; diseases prevention, market expansion to attrack increasing production and institutional capacity buiding as well as supporting policy. Transformation to revitalize of goats management should be bound by a standarized process and products which legally admitted by authority.

Keywords: friendship goats organization, goat farmers problems, planning

\section{PENDAHULUAN}

Pengalaman mengembangkan ternak besar, selama lebih dua dekade terakhir, menyisakan dilema ketergantungan pada impor. Oleh karena itu, perlu ada pilihan dan substitusi kepada jenis ternak yang lebih produktif dan relatif cepat memenuhi kebutuhan, seperti ternak kambing.
Secara teknis beternak kambing mempercepat siklus produksi dan upaya mengatasi masalah pangan (daging) dan gizi (susu). Alasannya ialah ternak kambing tidak membutuhkan lahan yang luas. Topografi Sumatera Barat yang bergelombang, berbukit dan sempit amat sesuai dengan karakter pemeliharaan kambing. Beberapa alasan lain seperti; siklus produksi ternak kambing bisa 
tiga kali dalam dua tahun, kerap beranak kembar, jinak dan bisa dikendalikan oleh perempuan, serta meminta modal usaha lebih sedikit ketimbang ternak besar. Semuanya menjadikan usaha beternak kambing lebih prospektif, mudah dan efektif.

Perspektif sosial ekonomi, usaha ternak kambing masih berada di bawah kendali peternak lokal. Tidak seperti struktul usaha ayam pedaging, aspek bibit dan pakan di hulu serta pasar di hilir dari ternak kambing masih dalam gengaman peternak. Kondisi sosial ekonomi ini membesarkan tekad untuk mengembangkan usaha, termasuk promosi melalui konsumsi produk lokal (Lukman, 2018).

Belakangan ini terjadi pula peningkatan distribusi dana sampai ke nagari dan desa, yang tentu membuka peluang usaha lebih leluasa. Terutama bagi kelompok usaha kecil dan upaya membantu mengatasi kemiskinan. Produk ternak kambing juga beragam seperti daging, susu dan kotoran yang multi guna. Dalam cara pandang seperti itu, Steinfeld et al. (2010) menulis bahwa usaha kecil, seperti ternak kambing, mampu bertahan dengan tiga alasan; mengatasi kendala pasar, pengurangan biaya transaksi dan kelembagaan yang berbeda bentuk dan fungsinya.

Rischkowsky (2017) menuliskan hasil kajian bahwa usaha ternak kambing di Ethiopia menunjukkan kinerja pemasaran yang dilematis. Oleh karena itu tingkat penghasilan peternak kurang memadai, meski harga pasar tinggi, dan kerap usaha peternak tiba tiba berhenti. Secara teknis sebabnya antara lain ialah; dukungan faktor input (bibit dan pakan) tidak tepat, pengetahuan dan manajemen usaha juga kurang. Kemudian akses kepada informasi dan pasar lemah, penyakit dan kematian ternak tinggi. Namun, permasalahan ini juga terkait dengan konsep kebijakan lebih tinggi, seperti; kapasitas institusi dan kebijakan yang kurang efektif. Selanjutnya kajian inovasi dan alih teknologi lemah; produk olahan dan pasar belum berkembang.
Akan tetapi seperti ditulis oleh Anderson dan Hoff (1993) bahwa pengembangan satu usaha ternak, dan agribisnis umumnya, perlu mengakomodasi kondisi lokal. Baik aspek fisik lingkungan, iklim dan cuaca maupun lembaga dan sosial budaya. Tuntutan karakter usaha ini membutuhkan peternak yang kreatif. Kemudian peternak mampu menyikapi permasalahan sekaligus muncul dengan solusi jitu yang berkelanjutan. Solusi ini menjadi rencana kegiatan yang jitu dan mendapat dukungan berbagai pihak.

Meski bertujuan untuk memberdayakan dan memperbaiki kesejahteraan, tanpa mengetahui kondisi lokal, apalagi melakukan duga-dugaan, niscaya tidak bisa mewujudkan cita cita. Oleh sebab itu, dilakukan satu studi awal mengidentifikasi apa saja permasalahan yang tengah dihadapi oleh peternak kambing di Sumatera Barat. Selain melakukan penguatan kapasitas peternak, melalui perencanaan partisipatif. tujuan kajian adalah:

1. Menemukan data untuk menyusun profil peternak kambing

2. Menggali informasi tentang masalah dan sebab sebab persoalan yang dihadapi oleh peternak kambing serta solusi mengatasinya.

Pada akhirnya diharapkan terbina lembaga peternak yang bisa mengendalikan manajemen bahan input usaha sekaligus pemasaran hasil dan inovasi bioteknologi.

\section{METODE}

Tahapan kerja untuk proses identifikasi masalah yang dihadapi oleh peternak kambing mencakup langkah seperti berikut. Seluruh tahapan berlangsung mulai pada awal tahun 2018. Pertama, diskusi untuk merevitalisasi organisasi peternak kambing provinsi Sumatera Barat. Meski ada lembaga, peternak merasa bahwa peran yang mereka terima belum optimal. Laboratorium Komunikasi dan Penyuluhan Pembangunan Fakultas Peternakan ikut menfasilitasi proses revitalisasi organisasi dengan cara saling 
belajar bersama.

Kedua, menyusun kuesioner untuk mengidentifikasi masalah peternak. Isi dari kuesioner merupakan komponen dasar memulai fasilitasi yang bersandar pada ilmu pengetahuan. Kuesioner disusun sesuai variabel, yaitu identitas demografi peternak (nama, umur, pendidikan, jumlah kelurga, jumlah dan komposisi ternak). Kemudian jenis produk usaha ternak. Selanjutnya masalah bibit, pakan, pemeliharaan, penyakit dan pasar serta kelembagaan.

Ketiga, membina tim kerja lapangan untuk mengumpulkan data primer dari empat daerah terpilih; Agam, Limapuluh kota, Payakumbuh dan Tanahdatar. Anggota tim ini terdiri dari empat mahasiswa Peternakan yang sedang mengerjakan tugas akhir dan magang. Mereka juga menimba pengalaman lapangan. Baik untuk mengenal ternak, mengolah susu kambing, atau melakukan penelitian. Kemudian, lima orang peternak terpilih, menjadi pemandu dilapangan. Dengan begitu, baik mahasiswa maupun peternak bisa berbagi dalam proses pembelajaran.

Keempat, pengumpulan data primer dengan bantuan kuesioner. Hal ini tidak saja bertujuan untuk meraih data dan identifikasi permasalahan. Sebab semua peternak anggota forum yang berjumlah 28 orang di temui. Proses juga berguna untuk berbagi informasi untuk perwujudan symetric information. Yaitu kondisi peternak saling up-date informasi, berbagi pengalaman, saling belajar bersama, dan menyadari posisi serta tujuan beternak secara utuh.

Kelima, mengolah data untuk memetakan masalah peternak yang menjadi basis bagi kegiatan berikutnya. Produknya berupa draft tertulis tentang permasalahan yang dihadapi peternak kambing. Pada satu sisi memperbaiki lembaga peternak berupa forum silaturahmi peternak kambing lingkup provinsi Sumatera Barat. Dilain pihak dapat menghasilkan dokumen perencanaan yang menjadi program kerja forum.

Keenam, konsultasi draft tertulis hasil identifikasi masalah dengan anggota forum. Tujuannya, selain untuk menajamkan pemahaman, konsultasi berguna menambah rasa peduli pada organisasi. Hasilnya sidang konsultasi menyepakati forum sebagai lembaga pembelajaran peternak kambing.

\section{HASIL DAN PEMBAHASAN}

Hasil identifikasi masalah yang dihadapi oleh peternak anggota forum silaturahmi peternak kambing provinsi Sumatera Barat terdiri dari tiga kategori; data usaha, data peternak dan masalah masalah yang menimpa usaha peternak.

\section{Kondisi usaha ternak kambing}

Peternak memelihara empat jenis ternak kambing, yaitu; peranakan etawah (PE), Saanen, Jawarandu/ Benggala, dan Kacang. Jumlah ternak yang dipelihara oleh anggota forum tercantum pada Tabel 1. Produk dari usaha ternak kambing ini meliputi tiga jenis, yaitu; daging, susu dan kotoran. Kendatipun begitu, produk daging bisa berupa kambing hidup atau kambing potong.

Menurut Suhubdy et al. (2018) ternak kambing dewasa ialah yang berumur 2-3 tahun dengan masa umur ekonomis selama 6-8 tahun. Maka, ternak kambing dapat dipelihara sampai selama 10 tahun. Sedangkan kambing muda berumur 1-2 tahun. Sesuai dengan kategori umut tersebut, data pada Tabel 1 menggambarkan bahwa kondisi usaha ternak kambing anggota forum cukup berimbang. Meski memusat pada seputar lokasi garis jalan daerah Bukittinggi dan Payakumbuh, komposisi ternak cukup memadai untuk dasar dasar pengembangan.

Hanya saja perhatian dalam bentuk fasilitasi pengembangan berupa perencanaan, pelaksanaan dan evaluasi kegiatan dengan fokus ternak kambing belum memadai. Pada umumnya para peternak memahami diri dan sesama peternak lain pada posisi sosial yang tidak berdaya. Ketidakberdayaan ini belum dilayani optimal, termasuk akses kepada sumberdaya. Khususnya 
Tabel 1. Jumlah, jenis kelamin dan kategori umur ternak kambing

\begin{tabular}{|c|c|c|c|c|c|}
\hline \multirow{2}{*}{ No } & \multirow{2}{*}{ Daerah /jenis kelamin } & \multicolumn{3}{|c|}{ Kategori umur } & \multirow{2}{*}{ Jumlah } \\
\hline & & Dewasa & Muda & Anak & \\
\hline \multirow{4}{*}{1} & Agam & & & & \\
\hline & Jantan & 20 & 34 & 34 & 88 \\
\hline & Betina & 162 & 29 & 45 & 236 \\
\hline & Sub-total & 182 & 63 & 79 & 324 \\
\hline \multirow{4}{*}{2} & 50 Kota/ Payakumbuh & & & & \\
\hline & Jantan & 21 & 20 & 42 & 83 \\
\hline & Betina & 236 & 75 & 43 & 354 \\
\hline & Sub-total & 257 & 95 & 85 & 437 \\
\hline \multirow{5}{*}{3} & Tanahdatar & & & & \\
\hline & Jantan & 6 & 2 & 1 & 9 \\
\hline & Betina & 34 & 11 & 7 & 52 \\
\hline & Sub-total & 40 & 13 & 8 & 61 \\
\hline & Jumlah & 479 & 171 & 172 & 822 \\
\hline
\end{tabular}

Sumber: Hasil kajian (2018)

untuk mentransformasi usaha dari kategori sampingan menjadi formal dan komersil.

Padahal pengalaman berbagai negara menunjukkan bahwa usaha ternak kambing lebih tepat pada peternak dengan sumberdaya terbatas. Memang, pengembangan masyarakat yang sukses fokus kepada perbaikan kompetensi sumberdya manusia dan kapasitas lembaga. Akan tetapi ternak kambing menjadi sarana untuk itu. Oleh karena usaha ternak kambing menjadi titik masuk menfasilitasi perbaikan kehidupan masyarakat miskin. Karena ia tidak meminta sumberdaya yang banyak dan justru bisa melibatkan lebih besar peserta. Apalagi, pengenalan solusi bioteknologi saja tidak memadai untuk mengatasi kemiskinan (Miller et al., 2012).

Kondisi usaha semacam itu membutuhkan beberapa perbaikan, seperti; (a) akses pada pelayanan pelatihan, bioteknologi, input usaha, kesehatan ternak, asuransi dan keuangan. (b) akses pada manajemen pemeliharaan ternak kambing secara berkelanjutan sesuai dengan tuntutan kondisi lokasi. (c) perbaikan kapasitas lembaga peternak termasuk manajemen dan kompetensi sumber daya manusia serta perannya dalam kawasan. (d) akses pada pasar susu, daging dan produk lain dengan dukungan kuat dari lembaga peternak dan pengambil kebijakan.

Khusus pada perbaikan kapasitas lembaga yang menjadi harapan dari peternak adalah forum atau asosiasi mampu meraih capaian seperti:

1. Peternak lebih mudah dalam proses penjualan susu kambing, kambing jantan dan pedaging serta pengadaan bibit yang berkualitas.

2. Peternak lebih leluasa dalam menggunakan unit usaha (koperasi) yang mampu menfasilitasi pemenuhan kebutuhan peternak kecil, seperti penanggulangan modal pengembangan usaha.

3. Lembaga peternak lebih mandiri yang bisa saling bekerjasama, serius dalam mengelola asosiasi, tidak mementingkan diri sendiri, dan menerima pembinaan dari pihak terkait.

\section{Profil peternak kambing}

Meskipun profil anggota forum silaturahmi peternak kambing provinsi Sumatera Barat amat menjanjikan, tetap masih perlu upaya perbaikan kompetensi dan 
Tabel 2. Profil anggota forum silaturahmi peternak kambing Sumatera Barat

\begin{tabular}{|c|c|c|c|c|c|c|c|}
\hline \multirow{2}{*}{ No } & \multirow{2}{*}{$\begin{array}{c}\text { Nama peternak/ } \\
\text { Lokasi usaha }\end{array}$} & \multirow{2}{*}{$\begin{array}{l}\text { Umur } \\
\text { (tahun) }\end{array}$} & \multirow{2}{*}{$\begin{array}{l}\text { Pendidikan } \\
\text { (tahun) }\end{array}$} & \multirow{2}{*}{ Latihan } & \multicolumn{2}{|c|}{ Pola usaha } & \multirow{2}{*}{$\begin{array}{l}\text { Jumlah } \\
\text { (orang) }\end{array}$} \\
\hline & & & & & Utama & Sambilan & \\
\hline & $\begin{array}{l}50 \text { Kota/ } \\
\text { Payakumbuh }\end{array}$ & & & & & & \\
\hline 1 & RA & 48 & SLTA & & $\mathrm{Ya}$ & & 6 \\
\hline 2 & DT & 44 & SLTA & & & $\begin{array}{c}\text { Pelatih OR. } \\
\text { Dekorasi }\end{array}$ & 6 \\
\hline 3 & WS & 46 & S1 Teknik & Magang & Ya & & 5 \\
\hline 4 & GF & 38 & SLTA & & & Security & 4 \\
\hline 5 & $\mathrm{RN}$ & 33 & SLTA & & $\mathrm{Ya}$ & & 4 \\
\hline 6 & $\mathrm{AZ}$ & 40 & SLTA & Disnak & & Dagang & 4 \\
\hline 7 & $\mathrm{MH}$ & 34 & SLTA & & Ya & & 3 \\
\hline 8 & $\mathrm{TS}$ & 34 & STM & & & Tani & 5 \\
\hline 9 & MU & 52 & SNAKMA & & & ASN & 5 \\
\hline 10 & IL & 43 & SMK & & & Tukang & 5 \\
\hline 11 & EM & 40 & SMP & & $\mathrm{Ya}$ & & 5 \\
\hline 12 & $\mathrm{BS}$ & 36 & SLTA & & Ya & & 4 \\
\hline \multirow[t]{3}{*}{13} & YF & 49 & MTsn & & $\mathrm{Ya}$ & & 5 \\
\hline & Sub-rata rata & 41,3 & SLTA & Belum & & Terpadu & 4,7 \\
\hline & Agam & & & & & & \\
\hline 14 & $\mathrm{AM}$ & 55 & S1Teknik & $\begin{array}{c}\text { Budidaya, } \\
\text { Olahan }\end{array}$ & $\mathrm{Ya}$ & & 4 \\
\hline 15 & $\mathrm{HO}$ & & S1 Ekonomi & & & Dagang & \\
\hline 16 & ED & 41 & STM & & Ya & & 4 \\
\hline 17 & MS & 33 & SLTA & & & Dagang & 3 \\
\hline 18 & AY & 29 & SLTP & Magang & $\mathrm{Ya}$ & & 3 \\
\hline 19 & NA & 29 & MAN & & & Wirausaha & 3 \\
\hline 20 & $\mathrm{HE}$ & 37 & SMK & & & Tani & 4 \\
\hline 21 & $\mathrm{RH}$ & 21 & MAN & & & Dagang & \\
\hline 22 & SR & 40 & S1 Agribisnis & $\begin{array}{c}\text { Manajemen } \\
\text { susu }\end{array}$ & & Guru & 5 \\
\hline 23 & MR & 29 & MAN & Olahan & & Tani & \\
\hline \multirow[t]{3}{*}{24} & JA & 29 & $\mathrm{~S} 1$ & & & Guru & \\
\hline & Sub-rata rata & 29 & SLTA & Sedang & & Terpadu & 2,4 \\
\hline & Tanahdatar & & & & & & \\
\hline 25 & HR & 51 & STM & $\begin{array}{c}\text { Manajemen, } \\
\text { olahan }\end{array}$ & & Guru & \\
\hline 26 & JA & 48 & SMP & & & Tani & 5 \\
\hline 27 & AY & 39 & $\mathrm{SD}$ & $\begin{array}{c}\text { Manajemen / } \\
\text { Kester }\end{array}$ & & Tani & 4 \\
\hline \multirow[t]{3}{*}{28} & RA & 34 & S1 Syariah & & & Baznas & 3 \\
\hline & Sub-rata rata & 43 & SMP & Terlatih & & Terpadu & 4 \\
\hline & Rata rata & 36,2 & SLTA & Sedang & & Terpadu & 3,8 \\
\hline
\end{tabular}

Sumber: Hasil kajian (2018)

kapasitas. Seperti Tabel 2, anggota peternak berusia pada kategori produktif (36,2 tahun) dan rata rata berpendidikan SLTA. Sebagian peternak mengelola usaha bersamaan dengan usaha lain atau secara terpadu. Sebagian sudah mendapatkan sentuhan pelatihan, baik dalam 
tata cara teknis mengelola usaha kambing atau juga mengolah susu. Rata rata peternak memiliki dua anak dengan rataan jumlah anggota keluarga (3,8 orang).

Akan tetapi, ketika membandingkan profil peternak pada tiga kawasan Agam, 50 Kota/ Payakumbuh dan Tanahdatar beberapa aspek dapat disajikan sebagai berikut. Memang usia dari peternak masuk kategori produktif. Tetapi rataan umur peternak Agam amat muda (29 tahun). Hal ini diikuti oleh peternak 50 Kota/ Payakumbuh dan terakhir Tanah datar. Fakta ini dapat dicermati sebagai arah pengembangan usaha, bahwa peternak relatif tua berlokasi di Tanah datar. Kemudian berdiffusi ke 50 Kota /Payakumbuh dan terus ke Agam bagian timur. Dilain pihak, dapat disebutkan bahwa proses kaderisasi para peternak di Agam berjalan cukup baik.

Kaderisasi peternak di Agam juga menarik lantaran pendidikan mereka. Meskipun rata rata tingkat SLTA, tetapi ada empat peternak yang sudah sarjana. Berbeda dengan Tanah Datar, walau rata rata pendidikan formal peternak setara SLTP, semua peternak sudah mengikuti latihan spesifik sebagai tambahan kompetensi. Kondisi pendidikan semacam ini relevan dengan pengolahan produk susu kambing. Oleh karena watak usaha apalagi mengolah susu amat membutuhkan rasa tanggungjawab, disiplin dan kebersihan.

Sisi penambahan kompetensi peternak melalui pelatihan mesti mendapat perhatian dari forum. Apalagi posisi usaha sedang berada dalam proses transformasi dari usaha sampingan menjadi usaha utama yang formal. Khususnya dalam pengukuhan standar produk dan proses dari pihak berwenang, seperti BPPOM. Dengan begitu, peluang pasar bakal terbuka lebih lebar. Pada gilirannya perluasan pasar menarik magnit usaha agar lebih dinamis.

Transformasi usaha ternak kambing secara menyeluruh juga membutuhkan pionir. Dengan kata lain ada beberapa peternak yang naik kelas secara struktural. Baik dihulu maupun dihilir. Dihilir, sejumlah peternak masuk kedalam kategori usaha pengolahan produk seperti susu dan daging atau kotoran ternak. Para peternak ini menjadi saluran/ channel bagi perbaikan mutu produk melalui proses yang standar dan tersertifikasi. Dihulu, ada pula peternak yang menjadi pelopor dan sumber perbaikan mutu bibit ternak kambing. Peternak menghasilkan bibit bersertifikat dan dirujuk oleh anggota forum.

Upaya untuk meningkatkan posisi sebagian peternak menjadi 'lokomotif' dalam usaha, baik dihulu maupun hilir, mesti sesuai dengan potensi, pengalaman dan target capaian. Dengan begitu, setiap tindak untuk melakukan kegiatan perlu disandarkan pada fakta dan data. Oleh karena usaha ternak kambing, atau agribisnis secara umum, terkait erat dengan banyak variabel/ peubah. Peubah ini tidak hanya aspek teknik memelihara ternak yang wataknya bernyawa, melainkan juga iklim dan cuaca, sosial budaya dan lembaga, serta interaksi antar sesamanya (Anderson dan Hoff, 1993). Jadi, agar supaya proses transformasi usaha tidak berdasarkan kepada dugaan, perlu dilakukan identifikasi persoalan yang dihadapi oleh peternak.

\section{Permasalahan peternak kambing}

Hasil identifikasi masalah yang dihadapi oleh para peternak kambing anggota dari forum silaturahmi meliputi beberapa hal, seperti; bibit, pakan, pasar produk dan dukungan dari kebijakan. Kemudian, sama seperti dilaporkan oleh Rischkowsky (2017), anggota forum juga perlu peningkatan kepedulian dalam antisipasi penyakit, pengenalan bioteknologi dan perbaikan nilai tambah produk.

Menurut Madarisa (2014) pola
penyusunan identifikasi masalah ini
mengikuti hasil pembelajaran dalam kegiatan
bantuan teknis USAID pada dua program;
LGSP (local governance support program)
dan Perform (performance oriented regional
management). Kemudian ia memadukan
dengan kerangka logis dari konsep ZOPP (ziel
orientarte projek planung), dari GTZ.


Tabel 3. Masalah, sebab dan solusi dalam bidang bibit ternak kambing

\begin{tabular}{|c|c|c|c|}
\hline No & Masalah & Sebab masalah & Alternatif solusi \\
\hline \multirow[t]{4}{*}{1} & $\begin{array}{l}\text { Bibit tidak } \\
\text { berkualitas }\end{array}$ & $\begin{array}{l}\text { Susah mendapatkan pejantan } \\
\text { dan indukan unggul. } \\
\text { Tidak sesuai dengan tujuan / } \\
\text { peruntukan pemeliharaan } \\
\text { (Potong, Breeding, Perah, dan } \\
\text { sebagainya) } \\
\text { Peternak hanya mengikuti } \\
\text { trend dan tidak memahami } \\
\text { tujuan beternak. } \\
\text { Mayoritas berangkat dari coba- } \\
\text { coba. }\end{array}$ & $\begin{array}{l}\text { 1. Perlu program dan acuan tata cara } \\
\text { pemeliharaan untuk ternak bibit } \\
\text { sampai bersertifikat dikalangan } \\
\text { peternak, dengan aktivitas: } \\
\text { - Mengukur } \\
\text { - Menimbang } \\
\text { - Mencatat } \\
\text { - Menseleksi/ memilih } \\
\text { 2. Pengadaan dan praktek mekanisme } \\
\text { perbaikan mutu bibit bagi anggota } \\
\text { forum }\end{array}$ \\
\hline & & $\begin{array}{l}\text { Bibit yang ada hanya hasil } \\
\text { dari peternakan rakyat yang } \\
\text { dikelola seadanya. }\end{array}$ & $\begin{array}{l}\text { 3. Mendorong anggota forum sebagai } \\
\text { pemasok dan pemelihara ternak } \\
\text { bibit unggul bersertifikat. }\end{array}$ \\
\hline & & $\begin{array}{l}\text { Sentra pembibitan kambing } \\
\text { belum optimal. }\end{array}$ & $\begin{array}{l}\text { 4. Kolaborasi dengan } \\
\text { Ruminansia kecil. }\end{array}$ \\
\hline & & $\begin{array}{l}\text { Pelaksanaan IB Kambing } \\
\text { belum ada. }\end{array}$ & $\begin{array}{l}\text { 5. Ujicoba dan kerjasama dengan BIB } \\
\text { dan Instansi terkait pengadaan } \\
\text { semen beku. }\end{array}$ \\
\hline 2 & $\begin{array}{l}\text { Bibit } \\
\text { bantuan } \\
\text { pemerintah } \\
\text { tidak } \\
\text { unggul } \\
\end{array}$ & $\begin{array}{l}\text { Bibit sering diterima dalam } \\
\text { kondisi lemah lantaran stress } \\
\text { dalam perjalanan jauh. } \\
\text { Tingkat kematian tinggi. } \\
\text { Tidak berkualitas. }\end{array}$ & $\begin{array}{l}\text { 1. Perbaikan prosedur perencanaan, } \\
\text { sistem kontrak pengadaan dan } \\
\text { standar perjalanan ternak. } \\
\text { 2. Pengawasan dari pihak independent } \\
\text { dan atau Forum/Asosiasi Peternak. }\end{array}$ \\
\hline
\end{tabular}

Sumber: Hasil kajian lapangan (2018)

Hasil kajian permasalahan bidang bibit ternak kambing disajikan pada Tabel 3. Fokus masalah berada pada anggota forum itu sendiri. Meskipun ada pula - dicetak miring - yang berada dalam ranah pemerintah daerah sebagai pengambil kebijakan. Walau sesungguhnya, peran dan fungsi perbaikan mutu bibit ternak berada dalam wewenang pemerintah (PP 48/2011), namun saat ada keterbatasan sumberdaya, peternak mesti bisa berinisiatif. Pengalaman peternak sapi Bali di Kabupaten Pasaman Barat untuk perbaikan mutu bibit ternak dapat dijadikan acuan/ benchmark (Hellyward et al., 2017). Dengan demikian peternak anggota forum silaturahmi lebih mandiri dalam mengendalikan kualitas bibit ternak kambing.

Permasalahan peternak kambing dalam aspek pakan dapat dilihat pada Tabel 4. Para peternak menghadapi permasalahan pada dua kategori; pakan hijauan dan konsentrat. Keterbatasan lahan untuk hijauan merupakan kendala utama. Sistem dan kewenangan penggunaan lahan - yang umumnya milik bersama/common property - perlu solusi. Intinya ialah akses peternak kepada penggunaan lahan untuk pakan. Dengan kata lain solusi kelembagaan perlu menjadi prioritas. Sedangkan penyediaan pakan konsentrat memusat pada upaya pengenalan teknologi pakan. Kontribusi para ahli dari lembaga kajian dan akademisi, mendesak dilakukan.

Uniknya, persoalan pakan menjadi esensil dalam pengembangan semua ternak, termasuk kambing. Oleh karena, pakan selain menjadi beban biaya paling tinggi, juga tidak bisa ditunda tunda. Tanpa pakan yang cukup, rasional biayanya dan bisa tersedia terus menerus, usaha ternak tidak bakal 
Tabel 4. Masalah, sebab dan solusi bidang pakan ternak kambing

\begin{tabular}{|c|c|c|c|}
\hline No & Masalah & Sebab masalah & Alternatif solusi \\
\hline \multirow[t]{3}{*}{1} & \multirow{3}{*}{$\begin{array}{l}\text { Susah } \\
\text { mendapatkan } \\
\text { hijuan yang } \\
\text { berkualitas } \\
\text { sehingga asupan } \\
\text { nutrisi ternak } \\
\text { dari hijauan tidak } \\
\text { tercukupi }\end{array}$} & $\begin{array}{l}\text { Mayoritas peternak tidak } \\
\text { memiliki lahan hijauan }\end{array}$ & $\begin{array}{l}\text { Perlu dicari lahan hijauan untuk } \\
\text { dijadikan kebun hijauan pakan ternak }\end{array}$ \\
\hline & & $\begin{array}{l}\text { Sulit mendapatkan lahan } \\
\text { untuk ditanami hijauan }\end{array}$ & $\begin{array}{l}\text { Dikembangkan unit produksi } \\
\text { pakan hijauan yang berkembang } \\
\text { menjadi Bank Pakan Bersama untuk } \\
\text { pemenuhan hijauan dalam wilayah } \\
\text { berdekatan }\end{array}$ \\
\hline & & $\begin{array}{l}\text { Kurangnya teknologi dalam } \\
\text { hal pengolahan pakan }\end{array}$ & $\begin{array}{l}\text { Perlu ilmu pengawetan pakan hijauan } \\
\text { seperti silase sehingga peternak } \\
\text { terbantu ketika paceklik hijauan } \\
\text { pakan ternak }\end{array}$ \\
\hline \multirow[t]{4}{*}{2} & \multirow{4}{*}{$\begin{array}{l}\text { Ampas tahu sulit } \\
\text { didapat lantaran } \\
\text { bersaing dengan } \\
\text { sesama peternak }\end{array}$} & Produksi ampas dari pabrik & Perlu dikembangkan formulasi pakan \\
\hline & & tahu & dapat mensubtitusi \\
\hline & & kambing yang perlu ampas & \\
\hline & & $\begin{array}{l}\text { tahu } \\
\text { Peternak belum kenal bahan } \\
\text { alternatif untuk ampas tahu } \\
\text { Mayoritas peternak belum } \\
\text { tersentuh teknologi olahan }\end{array}$ & $\begin{array}{l}\text { Pengenalan teknologi } \\
\text { mendesak dilakukan. }\end{array}$ \\
\hline \multirow[t]{5}{*}{3} & \multirow{5}{*}{$\begin{array}{l}\text { Harga pakan } \\
\text { konsentrat mahal, } \\
\text { maka peternak } \\
\text { kurang memakai } \\
\text { pakan konsentrat }\end{array}$} & $>\quad$ Mayoritas peternak & $>$ Diperlukan peran aktif pihak \\
\hline & & $\begin{array}{l}\text { belum tersentuh teknologi } \\
\text { pengolahan pakan }\end{array}$ & $\begin{array}{l}\text { akademis untuk mengembangkan } \\
\text { formulasi pakan alternatif: }\end{array}$ \\
\hline & & & $\begin{array}{l}\text { - tepat guna } \\
\text { - berharga murah }\end{array}$ \\
\hline & & & $\begin{array}{l}\text { - tersedia secara berkelanjutan pada } \\
\text { kawasan bersangkutan }\end{array}$ \\
\hline & & $\begin{array}{l}>\text { Ternak Kambing sulit } \\
\text { beradaptasi dengan } \\
\text { perubahan pakan yang baru }\end{array}$ & $\begin{array}{l}\text { > Perlu kajian seksama dan adaptasi } \\
\text { yang lama untuk mendapatkan } \\
\text { formulasi pakan konsentrat yang } \\
\text { palatabel. }\end{array}$ \\
\hline
\end{tabular}

Sumber: Hasil kajian (2018)

menghasilkan sesuai target.

Peternak juga kerap menghadapi masalah penyakit kambing. Esensi terjadinya penyakit berada pada dua posisi. Pertama, tingkat pengetahuan peternak masih rendah yang cenderung membawa pada tindak pengobatan lebih dominan dilakukan ketimbang upaya pencegahan. Kedua, hubungan peternak dengan tenaga medik ataupun paramedik veteriner belum optimal (Tabel 5). Konsekwensinya tenaga medik atau paramedik veteriner kurang tanggap ketika kejadian penyakit menimpa ternak kambing. Kemudian dengan jangkauan dari wilayah kerja yang luas untuk setiap petugas medik atau paramedik menyebabkan pelayanan belum maksimal. Disamping itu kompetensi dan pengalaman tenaga medik/paramedik ini dalam medikasi ternak kambing perlu ditingkatkan lantaran selama ini lebih terfokus pada ternak ruminansia besar (sapi dan kerbau).

Padahal penyakit ternak kambing kerap muncul yang sulit dikendalikan dan jelas berpengaruh kepada capaian ekonomis peternak. Jenis penyakit yang pernah ada terdiri dari; Kurap, Sakit Mata, Mencret, Bengkak kelenjar leher (pada anak yang baru 
Tabel 5. Masalah, sebab dan solusi bidang penyakit kambing

\begin{tabular}{|c|c|c|c|}
\hline No & Masalah & Sebab masalah & Alternatif solusi \\
\hline 1 & $\begin{array}{l}\text { Penyakit ternak } \\
\text { kambing sering } \\
\text { muncul }\end{array}$ & $\begin{array}{l}\text { Peternak kurang mengetahui tata } \\
\text { kelola dan manajemen kandang } \\
\text { mengantisipasi penyakit }\end{array}$ & $\begin{array}{lr}\text { Pelatihan } & \text { tentang } \\
\text { tatacara pengendalian } \\
\text { penyakit ternak }\end{array}$ \\
\hline 2 & $\begin{array}{l}\text { Penyakit ternak } \\
\text { kambing sulit } \\
\text { ditangani }\end{array}$ & $\begin{array}{l}\text { Tenaga paramedik veteriner kurang } \\
\text { respon dan sigap menanggapi keluhan } \\
\text { peternak ketika kejadian penyakit }\end{array}$ & $\begin{array}{l}\text { Peningkatan kompetensi } \\
\text { tenaga / petugas } \\
\text { kesehatan ternak }\end{array}$ \\
\hline 3 & $\begin{array}{l}\text { Penyakit ternak } \\
\text { menyebabkan } \\
\text { kerugian ekonomis }\end{array}$ & $\begin{array}{l}\text { Tindak pencegahan kerap terlambat } \\
\text { ketimbang pengobatan }\end{array}$ & $\begin{array}{l}\text { Peningkatan kompetensi } \\
\text { sumberdaya penyuluh } \\
\text { swadaya }\end{array}$ \\
\hline
\end{tabular}

Sumber: Hasil kajian (2018)

lahir) "yang sampai sekarang belum ditemukan solusi nya", Kelahiran Prematur, Mastitis, Kembung, Abortus dan Cacingan. Oleh karena itu, kewaspadaan perlu ditingkatkan dikalangan peternak. Caranya ialah jejaring komunikasi baik sesama peternak maupun dengan petugas perlu perbaikan.

Titik masuk perbaikan kompetensi peternak dan saluran komunikasi dalam mengatasi penyakit dapat dilakukan dengan pelatihan, magang dan kerja bersama/ kolaborasi bantuan teknis. Perbaikan ini juga mesti menyentuh tenaga kesehatan ternak dan penyuluh peternakan. Pada posisi itu perbaikan kapasitas dan kinerja lembaga terkait menjadi penting untuk sinkron dan bisa berkerjasama secara kolaboratif.

Permasalahan pemasaran produk ternak kambing baru meliputi tiga kategori; susu, bibit dan daging (Tabel 6). Padahal ada produk sampingan yang perlu dicermati lebih serius. Khususnya dalam cara pandang atau paradigma pembangunan pertanian yang berkelanjutan dan komitmen leisa (low external input for sustainable agriculture). Produknya adalah kotoran dan urine (pipis) kambing. Produk ini berguna untuk pupuk dan mencegah penyakit tanaman muda.

Ada fakta ditengah masyarakat yang mengesankan ternak kambing sebagai 'kelas kambing'. Suatu struktur sosial yang cenderung negatif, termasuk ocehan 'seperti bau kambing dan kandang kambing'. Keduanya berkonotasi kurang sedap lantaran tidak bersih dan centang perenang. Citra ternak kambing semacam ini menjadi kendala pula dalam pemasaran produk. Padahal, pasar merupakan sisi pendekatan baru mendorong pengembangan ternak kambing. Suatu paradigma berbeda dari upaya mendorong produksi yang terjadi selama ini. Chambers (1986) menyebutnya sebagai memulai dari belakang / put the last first. Arab News (2018) juga memberi jejak pengalaman cara cara memasarkan produk susu unta, yang pada sejumlah aspek relatif serupa karakteristiknya dengan pemasaran susu kambing.

Transformasi pendekatan pengembangan usaha ternak kambing dari dorongan produksi kepada daya hela pasar, amat ditentukan oleh set-up atau kiprah kembaga. Dalam hal ini asosiasi atau forum silaturahmi peternak kambing itu sendiri. Kondisi ril asosiasi, tidak lagi memberi fasilitasi yang memadai. Untungnya sebagian anggota dan pengurus menyadari keadaaan dan berusaha untuk merevitalisasi peran lembaga. Steinfeld, et al. (2010) menguatkan peran lembaga baru melalui pengelolaan jaminan input usaha, pemasaran dan dukungan ilmu pengetahuan.

Tindak aksi untuk memulai proses perbaikan diselenggarakan melalui identifikasi permasalahan peternak. Kajian dari kolaborasi dengan Laboratorium Komunikasi dan Penyuluhan Pembangunan ini membuktikan bahwa proses berjalan. Apalagi, seperti tulisan Juma $(2005 ; 2011)$ percepatan pengembangan dengan pengenalan bioteknologi mesti seiring, relevan dan mendapat dukungan dari dimensi 
Tabel 6. Masalah, sebab dan solusi bidang pemasaran produk ternak kambing

\begin{tabular}{|c|c|c|c|}
\hline No & Masalah & Sebab masalah & Alternatif solusi \\
\hline \multirow[t]{7}{*}{1} & SUSU & & \\
\hline & $\begin{array}{lr}\text { Permintaan } & \text { terhadap } \\
\text { susu kambing } & \text { sangat } \\
\text { berfluktuasi. } & \\
\end{array}$ & $\begin{array}{l}\text { Belum ada ritme } \\
\text { penjualan yang teratur. }\end{array}$ & $\begin{array}{l}\text { Kajian empiris atas dinamika harga } \\
\text { dan permintaan susu. }\end{array}$ \\
\hline & $\begin{array}{l}\text { Image masyarakat tentang } \\
\text { susu kambing kurang baik } \\
\text { (susu dianggap bersifat } \\
\text { panas). }\end{array}$ & \multirow{2}{*}{$\begin{array}{l}\text { Masyarakat belum } \\
\text { mengetahui } \\
\text { manfaat meminum } \\
\text { susu kambing } \\
\text { dan belum biasa } \\
\text { mengkonsumsinya. }\end{array}$} & \multirow{2}{*}{$\begin{array}{l}\text { - Perbaikan kreatifitas pelaku usaha } \\
\text { agar promosi lebih gencar, terpadu } \\
\text { dan terus menerus. } \\
\text { - Masyarakat dapat mengenal manfaat } \\
\text { meminum susu kambing. } \\
\text { - Perlu Penetapan Higien dan SOP } \\
\text { pemerahan susu yang terstandar dan } \\
\text { dipahami oleh seluruh peternak. }\end{array}$} \\
\hline & $\begin{array}{l}\text { Bau prengus membuat } \\
\text { masyarakat enggan membeli } \\
\text { susu kambing. }\end{array}$ & & \\
\hline & $\begin{array}{l}\text { Legalitas perizinan (izin } \\
\text { edar) susu masih sulit untuk } \\
\text { diakses/ diraih. }\end{array}$ & $\begin{array}{l}\text { Regulasi menjadi } \\
\text { penghambat untuk } \\
\text { penjualan susu. }\end{array}$ & $\begin{array}{l}\text { - Pemberi regulasi memberikan } \\
\text { pelatihan dan pembinaan dalam } \\
\text { standar mutu/penjualan susu. } \\
\text { - Perlu regulasi khusus untuk usaha } \\
\text { industri mikro kecil yang tidak } \\
\text { bisa disamaratakan dengan industri } \\
\text { besar. }\end{array}$ \\
\hline & $\begin{array}{l}\text { Belum adanya standar harga } \\
\text { susu. }\end{array}$ & $\begin{array}{l}\text { Harga jual susu oleh } \\
\text { peternak tidak sama }\end{array}$ & $\begin{array}{l}\text { Membuat kesepakatan bersama } \\
\text { menetapkan harga/mutu susu. }\end{array}$ \\
\hline & $\begin{array}{l}\text { Pendistribusian susu yang } \\
\text { masih sulit. }\end{array}$ & $\begin{array}{l}\text { Susu harus dipasarkan } \\
\text { dengan kondisi dingin/ } \\
\text { beku }\left(5^{\circ} \mathrm{C}\right) \text {. }\end{array}$ & $\begin{array}{l}\text { Pengenalan teknologi UHT (Ultra } \\
\text { High Temperature) memperpanjang } \\
\text { masa simpan susu segar. }\end{array}$ \\
\hline \multirow[t]{4}{*}{2} & BIBIT & & \\
\hline & $\begin{array}{l}\text { Toke masih menguasai } \\
\text { pasar bibit kambing. }\end{array}$ & $\begin{array}{l}\text { Peternak berposisi } \\
\text { proce taker dan toke } \\
\text { price maker. }\end{array}$ & $\begin{array}{l}\text { Pembekalan peternak dgn kemampuan } \\
\text { menaksir dan menghitung biaya } \\
\text { produksi. }\end{array}$ \\
\hline & $\begin{array}{l}\text { Bibit lebih mudah laku } \\
\text { ketika ada program } \\
\text { pengembangan dari instasi } \\
\text { terkait. }\end{array}$ & $\begin{array}{l}\text { masyarakat kurang } \\
\text { minat sehingga bibit } \\
\text { kambing lebih susah } \\
\text { dijual. }\end{array}$ & $\begin{array}{l}\text { Kebijakan pembelian bibit ternak } \\
\text { kepada peternak yang telah memiliki } \\
\text { SKLB. }\end{array}$ \\
\hline & $\begin{array}{l}\text { Harga bibit kambing belum } \\
\text { terstandar (bibit unggul } \\
\text { tidak dihargai dengan } \\
\text { semestinya). }\end{array}$ & $\begin{array}{l}\text { Pemahanan kurang } \\
\text { tentang mutu bibit dan } \\
\text { arti penting SKLB. }\end{array}$ & $\begin{array}{l}\text { Sosialisasi pentingnya SKLB (Surat } \\
\text { Keterangan Layak Bibit) kepada tiap } \\
\text { peternak sehingga bibit yang ada } \\
\text { terstandarisasi. }\end{array}$ \\
\hline \multirow[t]{4}{*}{3} & DAGING & & \\
\hline & \multirow{3}{*}{$\begin{array}{l}\text { Pemasaran kambing jantan } \\
\text { (daging) masih susah karena } \\
\text { image daging kambing } \\
\text { masih kurang baik (daging } \\
\text { kambing dianggap bersifat } \\
\text { "panas"). }\end{array}$} & \multirow{3}{*}{$\begin{array}{l}\text { Masyarakat masih } \\
\text { enggan untuk } \\
\text { mengkonsumsi daging } \\
\text { kambing. }\end{array}$} & $\begin{array}{l}\text { Promosi lebih gencar agar masyarakat } \\
\text { mau mengkonsumsi daging kambing } \\
\text { dengan mengenal manfaat dan } \\
\text { kelebihan daging kambing. }\end{array}$ \\
\hline & & & $\begin{array}{l}\text { Pendekatan kepada masyarakat untuk } \\
\text { berkurban kambing. }\end{array}$ \\
\hline & & & $\begin{array}{l}\text { Pendekatan kepada masyarakat untuk } \\
\text { aqiqah menggunakan kambing. }\end{array}$ \\
\hline
\end{tabular}

Sumber: Hasil kajian (2018)

kelembagaan (Tabel 7).

Memang kondisi kelembagaan peternak kambing lemah dan tidak fungsional. Aroma yang cenderung kepada penunggangan asosiasi untuk memenuhi kepentingan diri sendiri tercium kuat dan menyengat. Pada 
Tabel 7. Masalah, sebab dan solusi bidang kelembagaan peternak kambing

\begin{tabular}{|c|c|c|c|}
\hline No & Masalah & Sebab masalah & Alternatif solusi \\
\hline 1 & $\begin{array}{l}\text { Anggota asosiasi } \\
\text { kurang kompak } \\
\text { dan belum bisa } \\
\text { saling bekerja } \\
\text { sama }\end{array}$ & $\begin{array}{l}\text { Anggota masih } \\
\text { mengutamakan kepentingan } \\
\text { pribadi. } \\
\text { Pengurus menjadikan } \\
\text { asosiasi sebagai tameng } \\
\text { untuk memenuhi kebutuhan } \\
\text { pribadi. }\end{array}$ & $\begin{array}{l}\text { Pengembangan kapasitas anggota } \\
\text { dan lembaga sesuai kebutuhan dan } \\
\text { kondisi nyata. } \\
\text { Semua pihak berkomitmen untuk } \\
\text { berbagi sebagai proses belajar dan } \\
\text { menegakan aturan yg fair. }\end{array}$ \\
\hline 2 & $\begin{array}{l}\text { Kelompok/ } \\
\text { asosiasi kurang } \\
\text { tersosialisasi dan } \\
\text { tujuannya belum } \\
\text { jelas }\end{array}$ & $\begin{array}{l}\text { Hubungan emosional } \\
\text { diantara anggota asosiasi } \\
\text { belum terbina dengan baik. } \\
\text { Asosiasi belum mampu } \\
\text { memberikan manfaat bagi } \\
\text { anggota peternak. } \\
\text { Peternak enggan untuk } \\
\text { berkecimpung di asosiasi. }\end{array}$ & $\begin{array}{l}\text { Pengurus asosiasi mau berbagi } \\
\text { informasi yang bisa mencapai } \\
\text { posisi symetric information. } \\
\text { Menghasilkan agenda atau } \\
\text { program kerja forum dengan proses } \\
\text { penyadaran anggota. } \\
\text { Memperbaiki kinerja lembaga } \\
\text { berupa forum silaturahmi peternak. }\end{array}$ \\
\hline
\end{tabular}

Sumber: Hasil kajian (2018)

satu pihak, pengurus menerima sejumlah laba. Namun di lain segi, anggota justru merasakan takicuah dinan tarang. Kondisi tertipu dan merasa 'sekedar digunakan' untuk manfaat yang mereka tidak menikmati.

Kasus serupa terjadi di beberapa negara. Yesufu et al. (2017) menulis, sesungguhnya beternak kambing menguntungkan. Hanya saja upaya intensif perlu dilakukan agar usaha berjalan secara komersil. Sementara itu, beberapa hal yang mestinya dapat diatasi dengan bantuan forum justru tidak terjadi. Perhatikan misalnya, kompetensi dan soft skill tenaga kerja, standar gaji, pengenalan teknologi pengolahan pakan, akses sumber permodalan dan berbagi pengalaman.

Kemudian, untuk menghadapi perdagangan global produk susu tahun 2020 yang perlu kesiapan pelaku usaha dari dalam negeri. Kiprah organisasi, lobi, dan negosiasi kebijakan yang memihak kepentingan peternak mendesak dilakukan. Meski ada tanda tanda perlambatan karena pemotongan 150.000 ekor sapi perah di Selandia Baru dalam dua tahun kedepan lantaran sakit mycoplasma (Daily Sabah, 2018). Aspek ini tidak saja untuk transformasi ketengah pasar formal, tapi juga memastikan penyediaan input usaha, pemasaran dan pengenalan bioteknologi. Seluruh aktivitas membutuhkan peran forum yang kuat, kreatif, solid dan ramah kepada anggotanya.

\section{KESIMPULAN DAN SARAN}

Sebanyak 28 orang anggota peternak kambing yang menjadi anggota forum silaturahmi memelihara 822 ekor ternak. Komposisi ternak kambing yang di pelihara berimbang antara ternak dewasa, muda dan anak kambing. Arah difusi pemeliharaan terjadi dari Tanahdatar, ke 50 Kota dan Payakumbuh sampai ke Agam bagian timur. Bukti dari umur, pendidikan dan proses kaderisasi menunjukan arah difusi tersebut.

Masalah yang dihadapi oleh peternak kambing terdiri dari; perbibitan yang belum berkualitas. Intervensi berupa bantuan bibit dari pihak berwenang belum memadai. Kemudian pakan ternak kambing, termasuk jenis hijauan dan konsentrat. Selanjutnya masalah penyakit ternak yang mengerucut kepada dua hal; pengetahuan peternak dan respon petugas medik veteriner.

Masalah pasar produk usaha ternak kambing mencakup tiga jenis produk, susu, daging dan bibit. Padahal satu produk sampingan seperti kotoran belum dicermati. 
Akhirnya, semua masalah bermuara kepada tuntutan kinerja lembaga berupa forum/sosiasi peternak. Kiprah perkumpulan peternak kambing belum memenuhi harapan anggota. Dukungan kebijakan untuk percepatan penyelesaian masalah perlu lebih intensif dengan bantuan dokumen hasil identifikasi masalah ini.

\section{UCAPAN TERIMA KASIH}

Ucapan terima kasih kepada semua peternak yang memberi dua hal; komitmen untuk merevitalisasi forum silaturahmi dan berbagi pengalaman. Kemudian proses pengumpulan data yang melibatkan mahasiswa sambil magang pada kelompok peternak.

\section{DAFTAR PUSTAKA}

Anderson, J dan K. Hoff. 1993. Technological Change, Imperfect Markets and Agricultural Extension: An Overview, dalam. Hoff, K; A Braverman dan J Stiglitz (ed). The Economics of Rural Organization: Theory Practice and Policy. Oxford University. Oxford.

Arab News. 2018. How a Saudi dairy farmer brought camel milk to the US. May 31 . 2018.

Bank Dunia. 2007. World Development Report 2008. Agriculture for Development. The World Bank. Washington.

Chambers, R. 1986. Pembangunan pedesaan: Mulai dari belakang. LP3ES. Jakarta.

Daily Sabah. 2018. New Zealand to slaughter 150,000 cows to end disease. Ankara. Published in May 28, 2018.

Hellyward, J., Erinaldi, dan F. Madarisa, 2017. Dnamika pembangunan kawasan peternakan. Andalas University Press. Padang.

Juma, C. 2005. Biotechnology in a Globalizing World: The Coevolution of Technology and Social Institutions. BioScience:
Vol. 55, No. 3, pp. 265-272.

Juma, C. 2011. The New Harvest: Agricultural Innovation in Africa. Oxford University Press. New York.

Lukman, N. 2018. Dorong konsumsi susu segar lokal. Padang Ekspres. Selasa 5 Juni 2018. hal 4.

Madarisa, F. 2014. Teknik menyusun usulan kegiatan penyuluhan pertanian. Andalas University Press. Padang.

Miller, B., JP Dubeuf., JM Luginbuhl, dan J Capote. 2012. Scaling Up Goat Based Interventions to Benefit the Poor. A Report by the International Goat Association based on the IGA/IFAD Project, 2011-2012

Presiden Republik Indonesia. 2011. Peraturan pemerintah Republik Indonesia nomor 48 tahun 2011 tentang Sumberdaya genetik hewan dan perbibitan ternak. Lembaran negara nomor 123 tahun 2011.

Rischkowsky, B. 2017. Update on the sheep and goat meat value chain transformation in Ethiopia. Paper pada workshop on developing intervention packages for small ruminant value chain target sites, Addis Ababa, 19-20 April 2017.

Steinfeld, H., H. Mooney., F. Schneider, dan L. Neville. 2010. Livestock in changing lanscape: Drivers, Consequences and Responses. Vol 1. Island Press. Washington.

Suhubdy., Sukardono, dan A. Fachry. 2018. Pedoman perencanaan pembangunan peternakan Indonesia. Rajagrafindo Perkasa. Depok.

Yesufu, O. A., R. Kassali., F. J. Aremu, dan M. O. Ojo. 2017. Market Analysis of Smallholder Goat Enterprise under Tropical Conditions. DOI: 10.1515/ ats-2017-0013 Agricultura Tropica Et Subtropica 50/3, 121-127, 2017. 